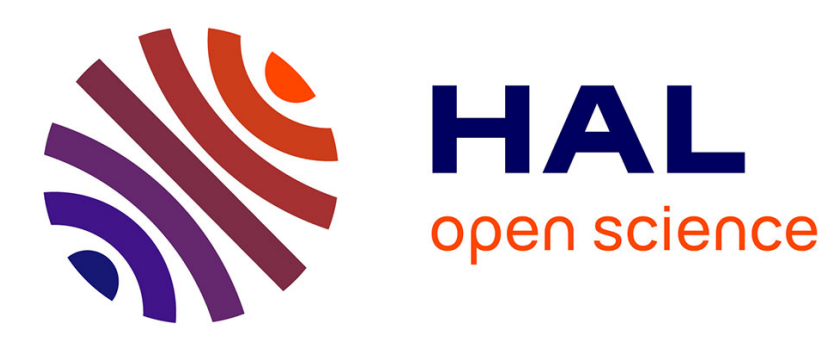

\title{
Application of Minor Actinides as Burnable Poisons in Sodium Fast Reactors
}

H. Guo, T. Kooyman, P. Sciora, L. Buiron

\section{To cite this version:}

H. Guo, T. Kooyman, P. Sciora, L. Buiron. Application of Minor Actinides as Burnable Poisons in Sodium Fast Reactors. Nuclear Technology, 2018, 205 (11), pp.1447-1459. 10.1080/00295450.2019.1611304 . cea-02339877

\section{HAL Id: cea-02339877 https://hal-cea.archives-ouvertes.fr/cea-02339877}

Submitted on 5 Nov 2019

HAL is a multi-disciplinary open access archive for the deposit and dissemination of scientific research documents, whether they are published or not. The documents may come from teaching and research institutions in France or abroad, or from public or private research centers.
L'archive ouverte pluridisciplinaire HAL, est destinée au dépôt et à la diffusion de documents scientifiques de niveau recherche, publiés ou non, émanant des établissements d'enseignement et de recherche français ou étrangers, des laboratoires publics ou privés. 


\title{
Application of Minor Actinides as Burnable Poisons in Sodium Fast Reactors
}

\author{
H. Guo, T. Kooyman, P. Sciora, L. Buiron \\ Alternative Energies and Atomic Energy Commission \\ CEA, DEN, SPRC, F-13108 Saint-Paul Les Durance Cedex \\ Email:hui.guo@cea.fr
}

\begin{abstract}
:
The reduction of the initial excess reactivity in fast reactor cores would enhance their inherent safety level as it would reduce the impact of a control rod withdrawal accident and lower the requirements on the absorption ability of control rods design. Compensation for burn-up reactivity loss is considered as a possible solution to limit initial excess reactivity. Minor actinides challenge the long-term nuclear waste management. Minor actinides can be transmuted from "absorber" isotopes to "fissile" isotopes, which show the possibility of their application as burnable poisons.

Two loading modes of minor actinides as burnable poisons are considered in this paper: the first one, denominated homogenous mode, mixes minor actinides with all the fuel and the second one, denominated hybrid mode, packages minor actinides in independent pins in the fuel assemblies. The content of americium or neptunium in these two designs is considered with regards to current technological feasibility, including burn-up, cladding stress, decay heat and the neutron source of the assemblies considered here. Both these two modes are able to compensate for the reactivity loss of an industrial power core and thus reduce excess reactivity at the beginning of cycle. The application of these designs in the cores with higher reactivity loss will be considered in next step work.

The impact of minor actinides loading on the core characteristics, including power distribution, material balance and feedback coefficient, are considered from the assembly level to the core level. The hybrid mode shows better management feasibility while the use of neptunium exhibits lower impacts on the current fuel recycling.
\end{abstract}

Key words: fast reactor, burnable poison, minor actinides, reactivity control 


\section{Introduction}

In our previous paper, boron carbide coupled with moderator is applied as burnable poison (BP) in a sodium fast reactor (SFR) to reduce core excess reactivity at the beginning of an equilibrium cycle (BOEC) and thus to reduce the effect of an inadvertent control rod withdrawal (CRW) (Guo et al, 2018). Now we seek to investigate a new burnable poison design.

As discussed in the previous paper (Guo et al, 2018), the candidates for the burnable poison should have a negative contribution to the chain reaction at the beginning of irradiation and this negative contribution must be reduced under irradiation or even be converted into positive contribution. The contribution to chain reaction of isotope i can be defined by plutonium equivalence $w_{i}$ as (Bussac and Reuss, 1978):

$$
w_{i}=\frac{\sigma_{i}^{+}-\sigma_{\mathrm{U} 238}^{+}}{\sigma_{\mathrm{Pu} 239}^{+}-\sigma_{\mathrm{U} 238}^{+}}
$$

Where $\sigma_{i}^{+}$is defined as $v \sigma_{i}^{\text {fission }}-\sigma_{i}^{\text {absorption }}$. In a classical SFR using plutonium based mixed oxide (MOX) fuel, ${ }^{239} \mathrm{Pu}$ and ${ }^{238} \mathrm{U}$ are chosen as the reference fissile and fertile isotopes because they are the principal contributors to the chain reaction.

As plutonium is re-used in a closed fuel cycle, long-term behavior of nuclear waste is driven by minor actinides (MA) (Kooyman et al., 2018), which challenges the recycling process and long-term underground storage because of their long half-life, high activity and important decay heat. The main minor actinides from current spent fuel are ${ }^{237} \mathrm{~Np},{ }^{241} \mathrm{Am}$ and ${ }^{243} \mathrm{Am}$.

The evolution chain of actinides is shown in Fig. 1 with their plutonium equivalence calculated for an oxide SFR neutron spectrum (See Section2.1). The evolution of plutonium equivalence of interesting isotope and their by-products under irradiation of fast spectrum is shown in Fig. 2 in which the fluence $6.0 \times 10^{23} \mathrm{n} / \mathrm{cm}^{2}$ is corresponding to 3000 days irradiation of $2.4 \times 10^{15} \mathrm{n} / \mathrm{cm}^{2} / \mathrm{s}$. The isotopes ${ }^{237} \mathrm{~Np},{ }^{241} \mathrm{Am}$ and ${ }^{243} \mathrm{Am}$ can be considered as "absorbers" in SFR due to their negative contribution to the chain reaction in fast spectrum. After neutron irradiation and decay, they can be transmuted into isotopes that have a positive contribution or "less negative" contribution to the chain reaction.

This transmutation from absorber isotopes to "fissile" isotopes reveals the possibility to use minor actinides as burnable poison in SFR. Therefore, this paper is aimed at studying the application of minor actinides as burnable poisons in fast reactors. The loading of minor actinides in the cores, the performance for the burnable poison objective and the impact on the core characteristics will be investigated.

Section 2 presents the calculation methods and the cores used here for the application of minor actinides as burnable poisons. The options used to load minor actinides in the core are discussed in Section 3.1 along with the various minor actinides feed available for use as burnable poisons. The burnable poisons designs are descripted in Section 3.3. The reactivity compensation ability of these designs is presented in Section 3.4, which demonstrates the capacity of minor actinides to be used as burnable poisons. Then, the design of these assemblies is analyzed to 
verify their feasibility with regards to current technological requirements (See Section 3.5). Finally, the impact of minor actinides loading on the core behavior is discussed in Section 3.6.

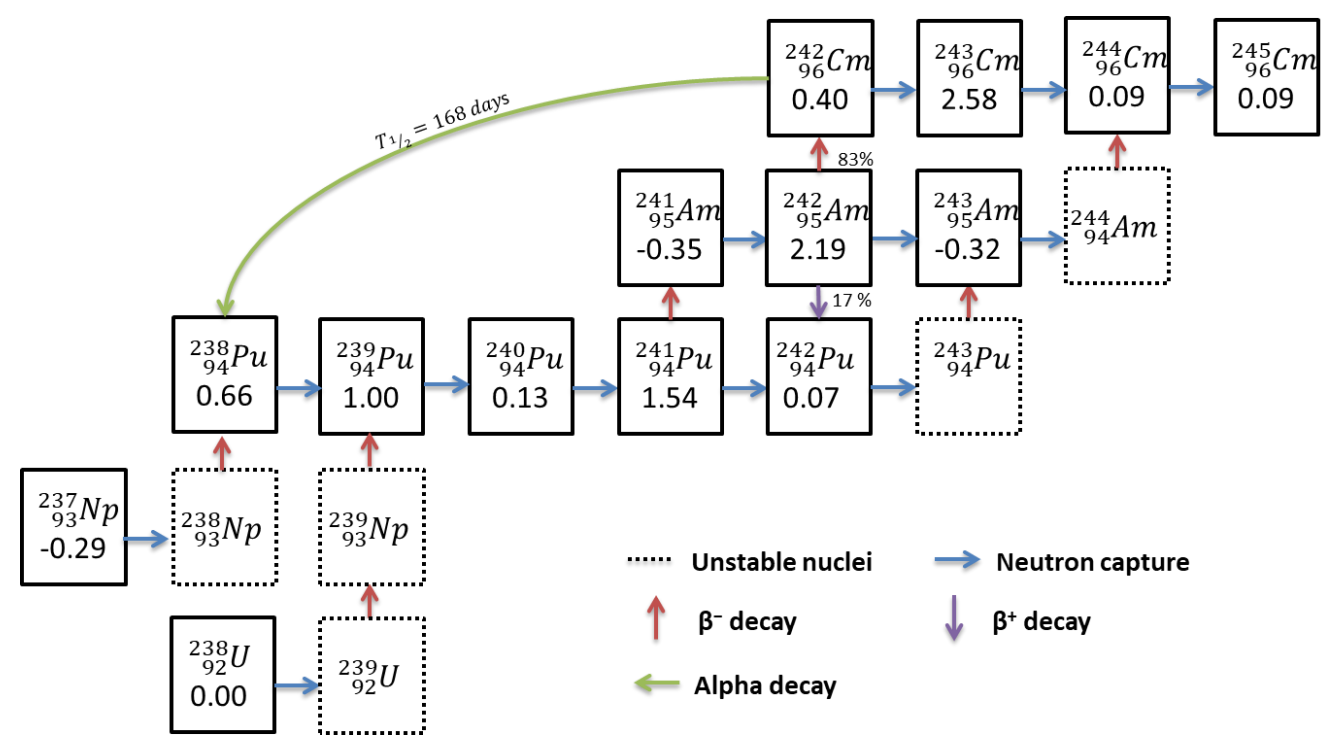

Fig. 1. The actinides burnup chain marked with plutonium equivalence in MOX SFR spectrum

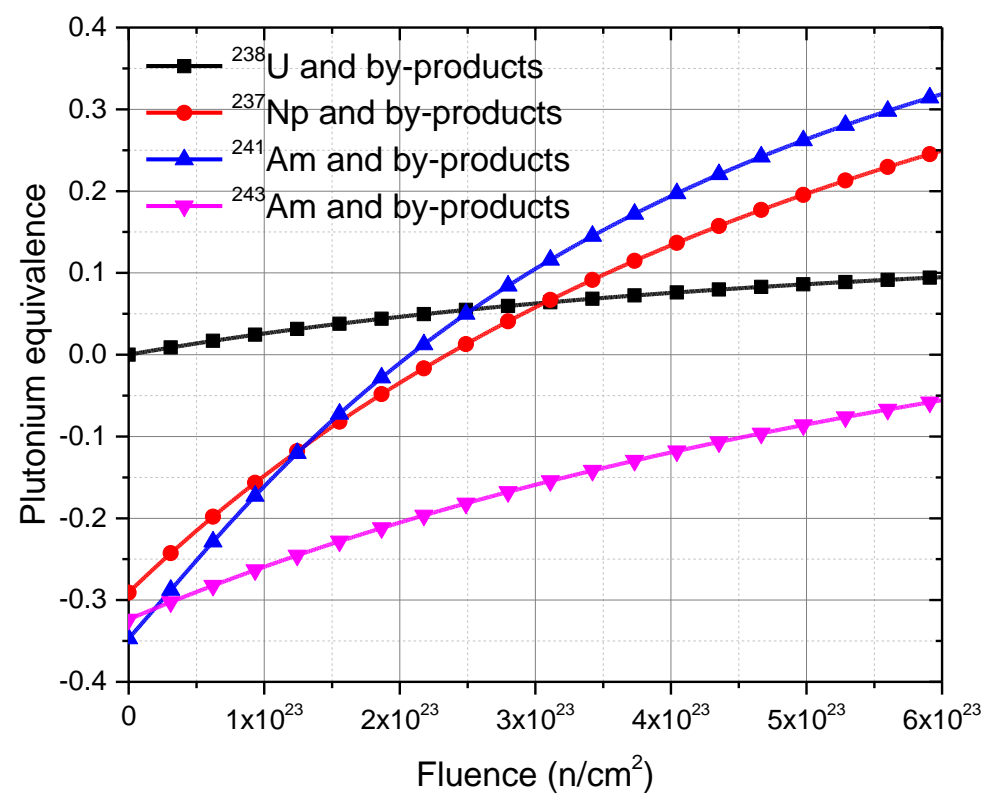

Fig. 2. Evolution of plutonium equivalence under irradiation of MOX SFR fast spectrum

\section{Methodologies}

\subsection{Reference core: $S F R-V 2 B$}

A core similar to the one described in our previous paper (Guo et al, 2018) and known as SFR-V2B SFR-V2B (3600 MWth) has been chosen as the target core in this work to apply minor 
actinides as burnable poison. This core has been deeply studied to achieve objectives defined for Generation-IV reactors (Mignot et al., 2008; Sciora et al., 2009). The objective of the burnable poison studied in the following is to reduce the reactivity loss for SFR-V2B to zero.

As shown in Fig. 3, SFR-V2B has 267 inner core assemblies and 186 outer core assemblies. After one cycle irradiation (410 Equivalent Full Power Days), $1 / 5^{\text {th }}$ of the core is refueled. The fuel assembly residence time in the core is 2050 EFPD and the average discharge burn-up is around $100 \mathrm{GWd} / \mathrm{t}$. SFR-V2B has two independent control rods systems: CSD (Control Shutdown System) and DSD (Diverse Shutdown System). We recall that the reference SFR-V2B core has $1177 \mathrm{pcm}$ of excess reactivity at BOEC of which $427 \mathrm{pcm}$ are reserved for the burn-up reactivity loss while $750 \mathrm{pcm}$ are reserved for operation margin and uncertainty margin. CSD2 (control rod at the interface inner and outer core) are inserted $25 \mathrm{~cm}$ at BOEC and be withdrawn slowly to compensate for burn-up reactivity loss.
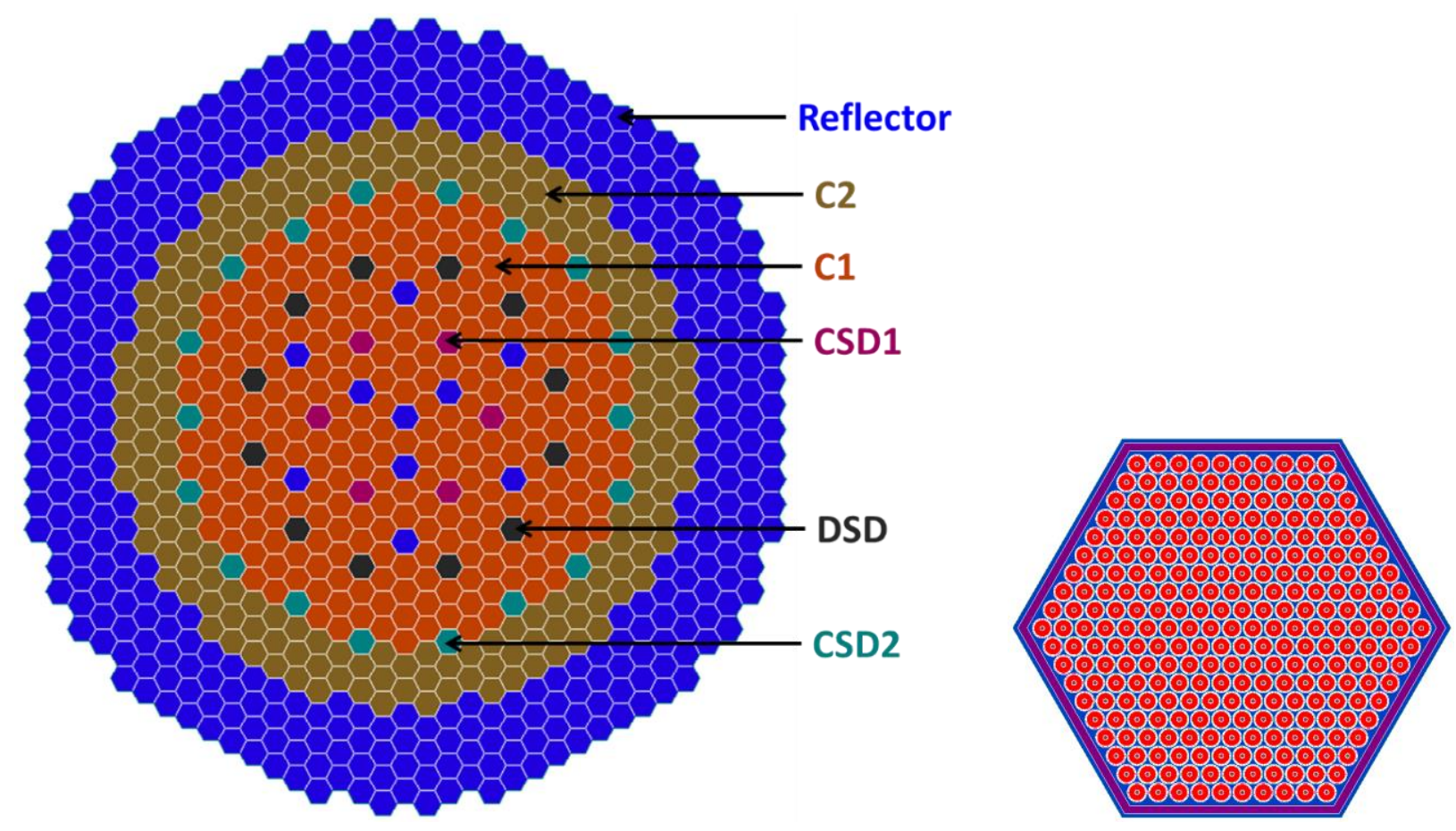

Fig. 3. The radial Layout of SFR-V2B core (left) and its standard fuel assembly (right)

\subsection{Calculation scheme}

Accurate and high performance neutronic simulation is the key for the evaluation of these innovative designs. The complex geometries of heterogeneous assemblies and the complete depletion chains for various isotopes should be considered for their depletion calculation. After careful consideration of the advantages and drawbacks of various tools, the recent deterministic code APOLLO3 (Golfier et al., 2009) is chosen for the neutronic simulations carried out in this paper. 
The calculation scheme includes two steps (Guo et al., 2018): lattice calculation to generate homogenized/collapsed cross-sections libraries and core calculation. The TDT (Three Dimensional Transport solver, coupling Collision Probability Method and Method of Characteristic) (Archier et al., 2016) based lattice calculation is able to simulate complex geometries with exact geometrical description and thereby compute accurate spatial self-shielding effects. A multi-group cross-section library tabulated with burn-up information of the calculated assembly is produced in the lattice step. Then, the $S_{N}$ solver MINARET (Moller et al., 2011) is used for 3D complete core simulation. The tabulated cross-section scheme improves significantly the accuracy of depletion calculation because it is able to transfer the variations in self-shielding from the lattice step to the core step, which is necessary for materials with significant change in absorption ability such as minor actinides and boron carbide. Such a scheme was already used and qualified in (Guo et al., 2018) for the design of innovative control rod designs.

\section{Results and discussion}

\subsection{Minor actinide loading modes}

There are different approaches to load these minor actinides in the core. The minor actinides can be loaded in special target assemblies located at the core periphery, which is the so-called heterogeneous transmutation mode. These special target assemblies can have flexible cycle length and limit the negative impacts of minor actinide loading on the fuel cycle since they can be recycled separately from the core fuel. Since the flux level at the core periphery is insufficient to ensure high transmutation performances, the addition of moderators has been proposed to accelerate transmutation (Grouiller et al., 2003; Kooyman et al., 2018). However, this loading mode would not be considered for burnable poison objective because the impact of minor actinides is limited by the low flux level. Moreover, the absorbers consumption and generation of fissile materials at the core periphery would increase the neutron leakage, which would reduce the positive contribution to the reactivity from the transmutation of minor actinides.

The homogeneous mode, which involves mixing minor actinides directly within the fuel, is also considered to take advantage of the high flux level in the core center. This approach would not modify the power distribution but would have a potential negative effect on the core feedback coefficients such as the sodium void worth and the Doppler constant (PALMIOTTI et al., 2011). Due to the important decay heat, activity, neutron source of minor actinides, this would increase the complexity of the entirety of the fuel cycle. These two modes to load minor actinides have been investigated in depth for transmutation purpose (OECD, 2012).

This work discusses a third option in which minor actinides are loaded in dedicated pins inside all fuel assemblies in the core as shown in Fig. 4. These pins with minor actinides are irradiated in a high flux environment and could theoretically be separated from other fuel pins before dissolution. However, their impact on the "safety" performances of the core should be 
considered with care. As this loading mode separates minor actinides from the other fuel pins (as in the heterogeneous) mode but load minor actinides in all the fuel assemblies (as homogeneous mode), it will labelled as "hybrid" mode in the following. This hybrid mode is investigated for burnable poisons objective in this paper to limit the reactivity swing of a fast reactor. Regarding the significant experience in MOX fuel manufacturing, the hybrid mode relies on the use of uranium oxide (UOX) as a matrix to incorporate the minor actinides in the oxide form, $\mathrm{UAmO}_{2}$ or $\mathrm{UNpO}_{2}$. In the present study, the hybrid mode substitutes only $6 \mathrm{MOX}$ pins with minor actinide pins for a first step of investigation.

The sensitivity study to the number of $\mathrm{UAmO}_{2}$ or $\mathrm{UNpO}_{2}$ pins is currently ongoing. Moreover, this hybrid mode enables independent pins to improve local neutronic characteristics such as $\mathrm{MgO}$ - and $\mathrm{ZrO}_{2}$-based fuel (Ronchi et al., 2003) or even the use of local moderator materials, which will be investigated in the future.

Both the homogeneous and hybrid approaches burnable poison performances will be investigated in this work.

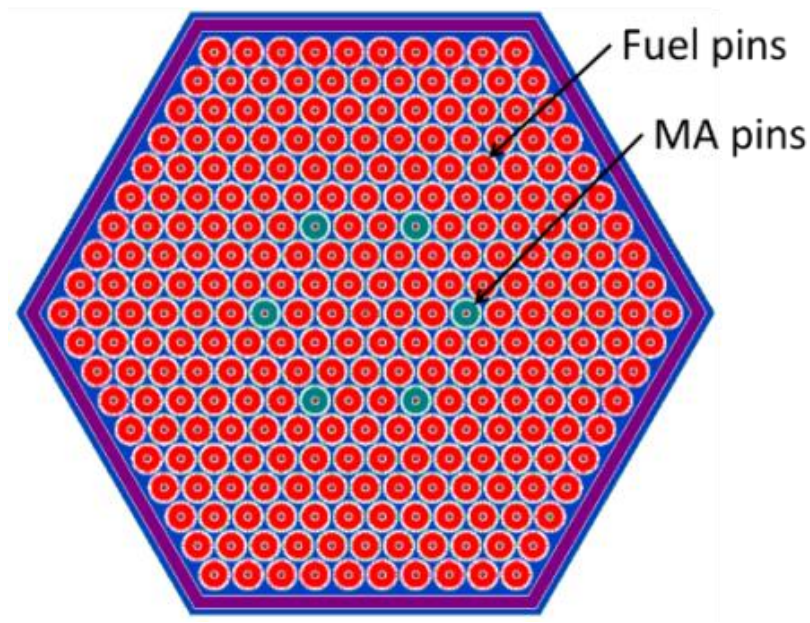

Fig. 4. Radial layout of the hybrid mode fuel assembly with 6 independent pins with minor actinides

\subsection{Minor actinides content for different loading modes}

This section will discuss the acceptable content of neptunium and americium in MOX matrix (corresponding to the homogeneous mode) or in UOX matrix (corresponding to the hybrid mode) to meet technological requirements on SFR fuel. The fuel of SFR-V2B, with $15 \%$ wt plutonium recycled form PWR MOX fuel (See Table 1) in uranium oxide is taken as reference MOX fuel. According to (Coquelet-Pascal et al., 2015), the neptunium is considered as $100 \%{ }^{237} \mathrm{~Np}$ while americium is considered as $75 \%{ }^{241} \mathrm{Am}$ and $25 \%{ }^{243} \mathrm{Am}$ in the following work.

Table 1. Isotopic compositions of plutonium recycled form PWR MOX fuel

\begin{tabular}{ccccccc}
\hline Isotopes & ${ }^{238} \mathrm{Pu}$ & ${ }^{239} \mathrm{Pu}$ & ${ }^{240} \mathrm{Pu}$ & ${ }^{241} \mathrm{Pu}$ & ${ }^{242} \mathrm{Pu}$ & ${ }^{241} \mathrm{Am}$ \\
Content $(\%$ wt) & 3.6 & 47.4 & 29.7 & 8.2 & 10.4 & 0.8 \\
\hline
\end{tabular}


Beside depleted uranium and reference SFR MOX, several minor actinide oxides are tested as independent pins in SFR-V2B fuel assembly using the APOLLO3-TDT solver (Schneider et al., 2016) and DARWIN-2.3 code (Tsilanizara et al., 2000) to evaluate their characteristics under irradiation in a typical SFR neutron environment and during cooling in the fuel reprocessing stage. There are multiple criterions that should be considered during the life of a fuel assembly from fabrication, irradiation, in-site cooling, transport, reprocessing to waste storage (Chabert et al., 2012).

The main gases released from reference SFR MOX fuel are gaseous fission products in the form of $\mathrm{Kr}$, Xe and $\mathrm{I}_{2}$. Oxide fuel requires closed pin design and thus the gas production must be limited to avoid over-pressurization of the pin. The gas release is not a significant issue to limit content of neptunium compared to decay heat. However, significant helium production will occur in the long transmutation chain of ${ }^{241} \mathrm{Am}$, mainly due to the decay of short-lived ${ }^{242} \mathrm{Cm}$, which is produced by capture on ${ }^{241} \mathrm{Am}$. In order to comply with the maximal cladding stress (i.e. $120 \mathrm{MPa}$ Tresca stress), the americium content is limited to $2.3 \%$ wt in MOX matrix and $5.9 \%$ wt in UOX matrix. The pressure allowance can be increased by extending the expansion room and adapting pins size, while this option is not considered in this paper.

After irradiation, the main technological requirements are related to decay heat, activity and neutron source limitations at the reprocessing stage. In the SFR-V2B case, the spent fuel is first moved to internal storage positions in the reactor vessel 15 days after the core shutdown. Then the spent fuel is cooled in the reactor vessel for about one fuel cycle, which is around 450 days including some operation time. Finally, it is washed and moved to a cooling pool for 5 years before being transported to the reprocessing plant. The decay heat per gram of fuel is used to consider not only global heat removal for fuel assembly but also local effect on special pins such as for the hybrid mode (Chabert et al., 2012):

- A $0.25 \mathrm{~W} / \mathrm{g}$ (40 kW per assembly) limit for assembly handing inside the reactor vessel (15 days cooling)

- A $0.047 \mathrm{~W} / \mathrm{g}(7.5 \mathrm{~kW}$ per assembly) limit for removal of the residual sodium in the assembly before it can be stored under water (operated after 450 days cooling in vessel, which is one SFR-V2B fuel cycle combined with refueling outage time)

The neptunium and americium mass content in UOX matrix (hybrid mode) is limited respectively to $16.3 \% \mathrm{wt}$ and $5.2 \% \mathrm{wt}$ by the $7.5 \mathrm{~kW}$ requirements for out-of-vessel removing. Their content in MOX matrix (homogenous mode) is further limited to $9.5 \%$ wt for neptunium and $3.0 \%$ wt for americium. These requirements could be lessened by improving fuel handing technologies or increasing the cooling time before operation.

The limitations on the activity and neutron source strongly depend on the industrial approach considered and the associated data is generally proprietary. The neutron source will not challenge the neptunium case, but it would be the most limiting factor in the ${ }^{243} \mathrm{Am}$ case due to the high intrinsic neutron source of accumulated ${ }^{244} \mathrm{Cm}$, which is produced by capture on ${ }^{243} \mathrm{Am}$. 
One advantage of the hybrid mode discussed here is that the $\mathrm{UNpO}_{2}$ or $\mathrm{UAmO}_{2}$ pins can be recycled separately in dedicated plants, which would minimize the impact on the fuel cycle especially for activity and neutron source aspects.

In summary, as shown in Table 2, the neptunium content is limited to $9.5 \%$ wt for homogeneous mode (MOX matrix) and $16.3 \%$ wt for hybrid mode (UOX matrix). The americium content is limited to $2.3 \% \mathrm{wt}$ for homogeneous mode and $5.2 \% \mathrm{wt}$ for hybrid mode. The most limiting requirement is the decay heat removal that requires improvement on the fuel cooling technologies. This discussion is based on loading minor actinides in UOX or MOX to satisfy current technological requirements that vary with designs and technological options. Therefore, this discussion gives only coarse estimations and it is necessary to carry out several calculations assess the feasibility of detailed designs in Section 3.5.

Table 2. Maximal content of minor actinides in homogeneous and hybrid loading mode

\begin{tabular}{ccc}
\hline & Homogeneous mode (MOX matrix) & Hybrid mode (UOX matrix) \\
\hline${ }^{237} \mathrm{~Np}$ & $9.5 \%$ wt $(\mathrm{DH})$ & $16.3 \%$ wt (DH) \\
${ }^{241} \mathrm{Am}_{0.75}{ }^{243} \mathrm{Am}_{0.25}$ & $2.3 \%$ wt $(\mathrm{GR})$ & $5.2 \%$ wt (DH) \\
\hline
\end{tabular}

Remarks: DH means that this content is limited by decay heat; GR means that this content is limited by gas release.

\subsection{Design description}

Using the loading modes detailed in section 3.1, this paragraph presents 6 burnable poison designs with minor actinides that will be investigated in the following sections. These designs are based on depleted uranium oxide with different content in plutonium or minor actinides. Table 3 summarizes the designs of fuel assembly in the inner core. The plutonium content is adjusted to obtain the same end of equilibrium reactivity as for the reference case that is about $750 \mathrm{pcm}$ to cover uncertainty and operation margin. For each burnable poison design, the outer core is also loaded with burnable poisons but with a higher plutonium content to optimize power distribution. In the reference core, the ratio of plutonium content between outer core and inner core is 1.19. Since the minor actinides are loaded in the entire core and only lead to small differences on plutonium content from the reference core, all burnable poison designs keep the same ratio to optimize power distribution.

MABP1 and MABP2 are related to the homogeneous mode to load neptunium while MABP3 and MABP4 load americium. The $0.77 \%$ wt content is chosen to enable MABP1 with enough ability to compensate for the reactivity loss for SFR-V2B (See Section 3.4). MABP3 load the same content in americium for comparison purpose. MABP4 loads the maximal content $(2.32 \% \mathrm{wt})$ of americium to show the maximal potential reactivity compensation ability. Current technologies enable higher content of neptunium, but only the conservative loading is considered in MABP2 for comparison purpose with americium.

MABP5, MABP6 and MABP7 use hybrid mode with 6 independent pins in maximal content of minor actinide. The characteristics of all these fuel pins are investigated in this paper 
to assess their feasibility within the current industrial limitations (See Section 3.5).

Table 3. Description of burnable poison designs

\begin{tabular}{|c|c|c|c|c|c|}
\hline Design & Mode & Inner fuel assembly & $\mathrm{Pu}(\mathrm{kg})$ & $\operatorname{Am}(\mathrm{kg})$ & $\mathrm{Np}(\mathrm{kg})$ \\
\hline Reference & & $271(14.431 \%$ wt $\mathrm{Pu})$ pins & 12656 & 0 & 0 \\
\hline MABP1 & Homo & $271(0.77 \%$ wt $\mathrm{Np}+14.254 \% \mathrm{Pu})$ pins & 12500 & 0 & 607 \\
\hline MABP2 & Homo & $271(2.32 \%$ wt $\mathrm{Np}+14.2 \%$ wt $\mathrm{Pu})$ pins & 12453 & 0 & 1822 \\
\hline MABP3 & Homo & $271(0.77 \%$ wt Am $+14.17 \%$ wt Pu $)$ pins & 12430 & 619 & 0 \\
\hline MABP4 & Homo & $271(2.32 \%$ wt Am $+13.99 \%$ wt Pu $)$ pins & 12267 & 1857 & 0 \\
\hline MABP5 & Hybrid & $\begin{array}{c}6 \text { depleted UOX pins } \\
265(14.60 \% \text { wt } \mathrm{Pu}) \text { pins }\end{array}$ & 12521 & 0 & 0 \\
\hline MABP6 & Hybrid & $\begin{array}{c}6(18.00 \% \text { wt Np) pins } \\
265(14.58 \% \text { wt Pu }) \text { pins }\end{array}$ & 12507 & 0 & 333 \\
\hline MABP7 & Hybrid & $\begin{array}{c}6(6.00 \% \text { wt Am }) \text { pins } \\
265(14.49 \% \text { wt Pu }) \text { pins }\end{array}$ & 12429 & 113 & 0 \\
\hline
\end{tabular}

Remark: Pu is plutonium recycled form PWR MOX fuel as shown in Table $1 ; \mathrm{Np}$ is ${ }^{237} \mathrm{~Np}$; Am is $75 \%{ }^{241} \mathrm{Am}$ and $25 \%{ }^{243} \mathrm{Am}$; Homo is the homogenous loading mode.

\subsection{Reactivity compensation ability}

The reactivity at BOEC and EOEC (both with the control rods parked at the top of fissile zone) of the reference case and different designs with burnable poisons are listed in Table 4 in which the minimal excess positive reactivity of core is set at about $750 \mathrm{pcm}$ by adjusting the plutonium content. The reactivity variation is defined as the difference of reactivity between EOEC and BOEC. The compensation ability, the key parameter to evaluate the capability of burnable poisons, is the difference in the reactivity variation compared to reference case.

For the reference case, the core reactivity decreases from $1177 \mathrm{pcm}$ to $750 \mathrm{pcm}$. This reactivity loss is compensated by withdrawing the CSD2 from $25 \mathrm{~cm}$ insertion to the top of the fissile zone. The MABP1 is an ideal burnable poison design for SFR-V2B, because its negative reactivity contribution decreases at the same rate as the excess positive reactivity of the core is depleted. There is no excess positive reactivity during all the cycle. For MABP1, SFR-V2B requires no control rods movement to compensate for the burn-up reactivity loss.

The core reactivity of MABP2, MABP3 and MABP4 increases with its burn-up. As self-breeder core, the initial SFR-V2B design becomes breeder core when a large amount of MA is introduced. These three designs are not adequate for fine tuning purpose regarding the low reactivity swing of SFR-V2B. However, this kind of solution could be interesting for a larger reactivity swing in case of plutonium quality change or core design adaptation (start-up core, fleet deployment stage, etc.). For instance, these burnable poison configurations could be tested for the ASTRID core for which the reactivity loss is around $1400 \mathrm{pcm}$ per cycle (Chenaud et al., 2013). 
MABP5, MABP6 and MABP7 configurations are less "efficient" compared to MABP1, but they also reduce the BOEC excess reactivity. For these hybrid modes, the minor actinides content is limited unless improvement on the fuel handing and reprocessing technologies can be achieved. However, the number of $\mathrm{UAmO}_{2}$ or $\mathrm{UNpO}_{2}$ pins could be increased to improve their compensation ability. This option requires further investigation.

Table 4. Reactivity compensation ability (Unit: pcm)

\begin{tabular}{ccccc}
\hline Design & BOEC & EOEC & $\begin{array}{c}\text { Reactivity } \\
\text { Variation }\end{array}$ & $\begin{array}{c}\text { Compensation } \\
\text { Ability }\end{array}$ \\
\hline Reference & 1177 & 750 & -427 & -- \\
MABP1 & 850 & 838 & -12 & 415 \\
MABP2 & 729 & 1092 & 363 & 789 \\
MABP3 & 760 & 1011 & 252 & 678 \\
MABP4 & 536 & 1634 & 1098 & 1525 \\
MABP5 & 925 & 748 & -177 & 250 \\
MABP6 & 882 & 817 & -65 & 362 \\
MABP7 & 859 & 732 & -127 & 299 \\
\hline
\end{tabular}

Firstly, as shown in Fig. $1,{ }^{241} \mathrm{Am}$, which as a plutonium equivalence of -0.35 , has a more negative contribution to the chain reaction than ${ }^{237} \mathrm{~Np}$ for which the plutonium equivalence is -0.29 . The one-group capture cross-section for ${ }^{241} \mathrm{Am}$ and ${ }^{237} \mathrm{~Np}$ are respectively 1.85 barn and 1.61 barn. Moreover, the capture product of ${ }^{241} \mathrm{Am}$ is ${ }^{242} \mathrm{Am}$ which has a plutonium equivalence of 2.19 while the production of ${ }^{237} \mathrm{~Np}$ is ${ }^{238} \mathrm{Pu}$, which the plutonium equivalence is 0.66 . Consequently, americium has better compensation ability than neptunium if the same quantity is loaded. However, a higher content of neptunium is allowed due to the issues on the gas release, decay heat and neutron source. As discussed in Section 3.2, the maximum content is $10 \% \mathrm{wt}$ for neptunium using homogeneous mode while it is only $3 \% \mathrm{wt}$ for americium. Therefore, with the current technological limitations, neptunium has equivalent or even better compensation ability compared to americium.

With $0.77 \% \mathrm{wt}$ addition of neptunium in all the fuel assemblies, the reactivity variation for SFR-V2B case is close to zero. A $2.32 \%$ wt addition of americium in all the fuel shows compensation ability about $1500 \mathrm{pcm}$. With 6 fuel pins (among 271) substituted by $\mathrm{U}_{0.82} \mathrm{~Np}_{0.18} \mathrm{O}_{2}$ or $\mathrm{U}_{0.94} \mathrm{Am}_{0.06} \mathrm{O}_{2}$ pins, the hybrid mode shows a large compensation ability. Among designs investigated in this paper, the homogeneous mode shows a better compensation ability than the hybrid mode. However, hybrid approach is more efficient than homogeneous approach in terms of compensation ability per unit of minor actinides loaded. For instance, the quantity of neptunium in the hybrid mode with 6 independent pins (MABP6) is only $55 \%$ of that the homogeneous mode with $0.77 \%$ wt addition in all the fuel (MABP1), but the compensation ability of MABP6 is $87 \%$ of that with MABP1.Moreover, the high content of minor actinides in 
independent pin would reduce the manufacturing constraints and give additional flexibility to adjust the quantity of minor actinides.

\subsection{Technological feasibility of fuel assemblies}

Section 3.2 has discussed preliminarily the expected minor actinide content in homogeneous mode or hybrid mode. In this section, the characteristics designs in Table 3 are analyzed under neutron irradiation and during cooling to investigate their technological feasibility in current industrial background. Beside the reference fuel pin, only the pins with addition of minor actinides from MABP2, MABP4, MABP6 and MABP7 are investigated in the following because their technological feasibility is currently not guaranteed.

The characteristics of fuel assembly of these designs are calculated with APOLLO3 TDT solver in an infinite lattice from $0 \mathrm{GWd} / \mathrm{t}$ to $150 \mathrm{GWd} / \mathrm{t}$ at 50 watts per gram of heavy nuclei which is equivalent to the average value in the reference core. The compositions of irradiated materials $100 \mathrm{GWd} / \mathrm{t}$ are fed to DARWIN for the long-term cooling performance analysis.

\subsubsection{Flux and power distribution in assembly}

The flux and power distribution in the reference SFR fuel assemblies are quite flat during the whole irradiation time. The homogeneous mode has no influence on the spatial flux and power distribution because the minor actinides are added into every fuel pin. However, the hybrid mode adds significant amounts of minor actinides in selected pins, which will influence the power distribution in the assembly. Therefore, this section is devoted to compare the flux and power distribution in MABP6 and reference fuel assembly.

The Fig. 5 shows the spatial distribution of the discrepancy in flux between MABP6

assembly and reference assembly i.e. $\frac{v^{M A B P 6}-v^{\text {reference }}}{v^{\text {reference }}} \times 100$. The independent pin with $18 \%$ wt ${ }^{237} \mathrm{~Np}$ increase has no significant influence on the flux distribution at different burn-up level.

The average linear heat rating in the pins of the reference designs or the designs with homogeneous mode is around $299 \mathrm{~W} / \mathrm{cm}$. However, for the fuel pin as $18 \% \mathrm{wt} \mathrm{Np}$ in UOX matrix (MABP6), the linear heat rating increases from $140 \mathrm{~W} / \mathrm{cm}$ at 0 day to $334 \mathrm{~W} / \mathrm{cm}$ at 2000 days. Similarly, the linear heat rating increases from $92 \mathrm{~W} / \mathrm{cm}$ to $266 \mathrm{~W} / \mathrm{cm}$ for the fuel pin with $6 \%$ wt Am content in UOX matrix (MABP7). The linear heat rate in the burnable poisons pins appears as acceptable compared to the maximal heat rate in the core. The impact of pins with minor actinides on its neighboring fuel pins is not significant. The loading of additional independent pins with minor actinides is feasible but may require some design modifications in order to limit their linear power rate variation during irradiation 

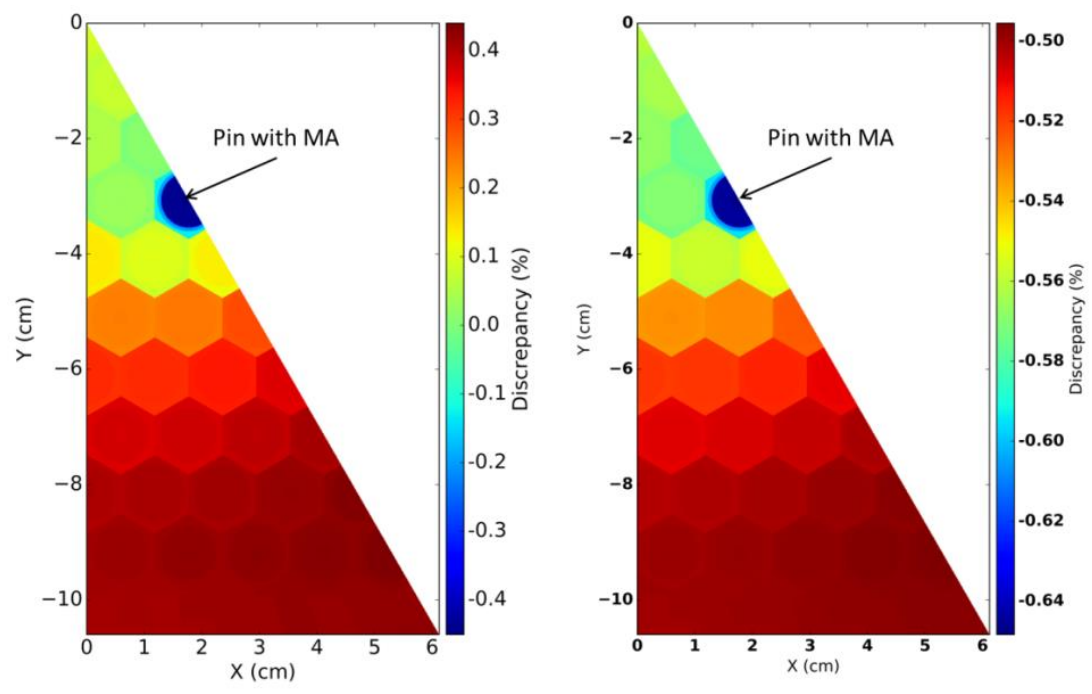

Fig. 5. The discrepancy in flux between MABP6 and reference fuel assembly at $0 \mathrm{GWd} / \mathrm{t}$ (left) and at $100 \mathrm{GWd} / \mathrm{t}$ (right)
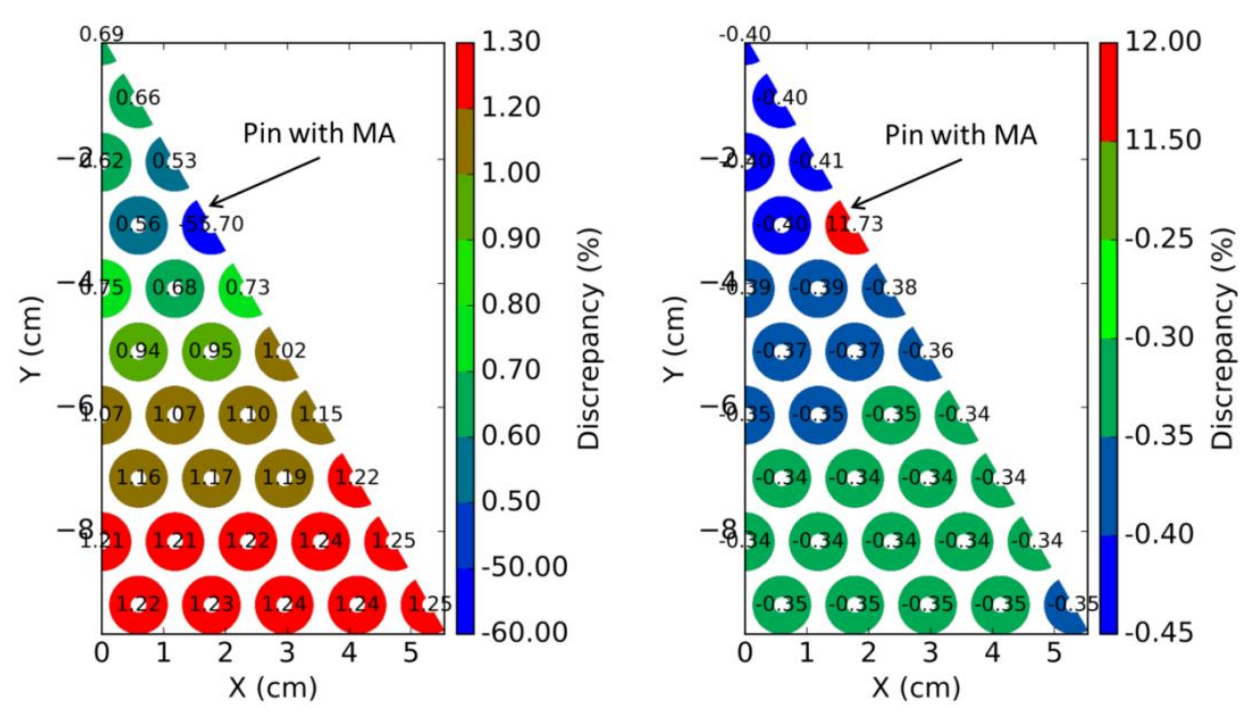

Fig. 6. The discrepancy in the linear heat rating between MABP6 and reference fuel assembly at 0 GWd/t (left) and at $100 \mathrm{GWd} / \mathrm{t}$ (right)

\subsubsection{Characteristics under irradiation}

Based on current fuel technological limitations, the designed average burn-up for SFR-V2B is about $100 \mathrm{GWd} / \mathrm{t}$ while maximal burn-up is $150 \mathrm{GWd} / \mathrm{t}$. The local burn-up of a fuel pin and of a minor actinide bearing pin at a similar position in the core is compared in Fig. 7. The burn-up of fuel pins with minor actinides in homogeneous mode varies almost the same as reference fuel pin because the power distribution is flat in all the fuel assembly for homogeneous mode. Yet, the burn-up of $\mathrm{U}_{0.82} \mathrm{~Np}_{0.18} \mathrm{O}_{2}$ or $\mathrm{U}_{0.94} \mathrm{Am}_{0.06} \mathrm{O}_{2}$ pin in the hybrid mode is lower than that the one 
of reference pins although the power in these pins increases significantly along the irradiation.

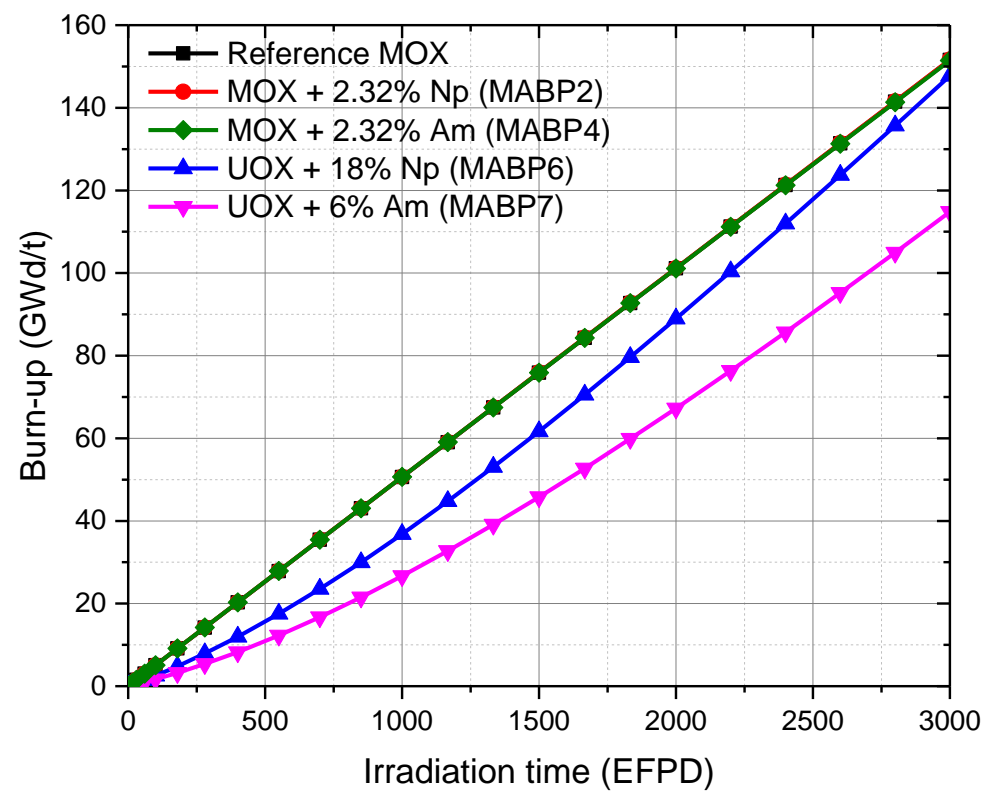

Fig. 7. Evolution of burn-up under irradiation

As shown in Fig. 8, the fuel centerline temperature for $\mathrm{U}_{0.82} \mathrm{~Np}_{0.18} \mathrm{O}_{2}$ or $\mathrm{U}_{0.94} \mathrm{Am}_{0.06} \mathrm{O}_{2}$ pin increases significantly with irradiation but remains always lower than the melting temperature. Finally, the melting margin for the fuel assembly of MABP6 is reduced $200 \mathrm{~K}$ compared to reference fuel assembly, which require future works to improve the heat transfer or to limit linear heat rating in the pins with minor actinides.

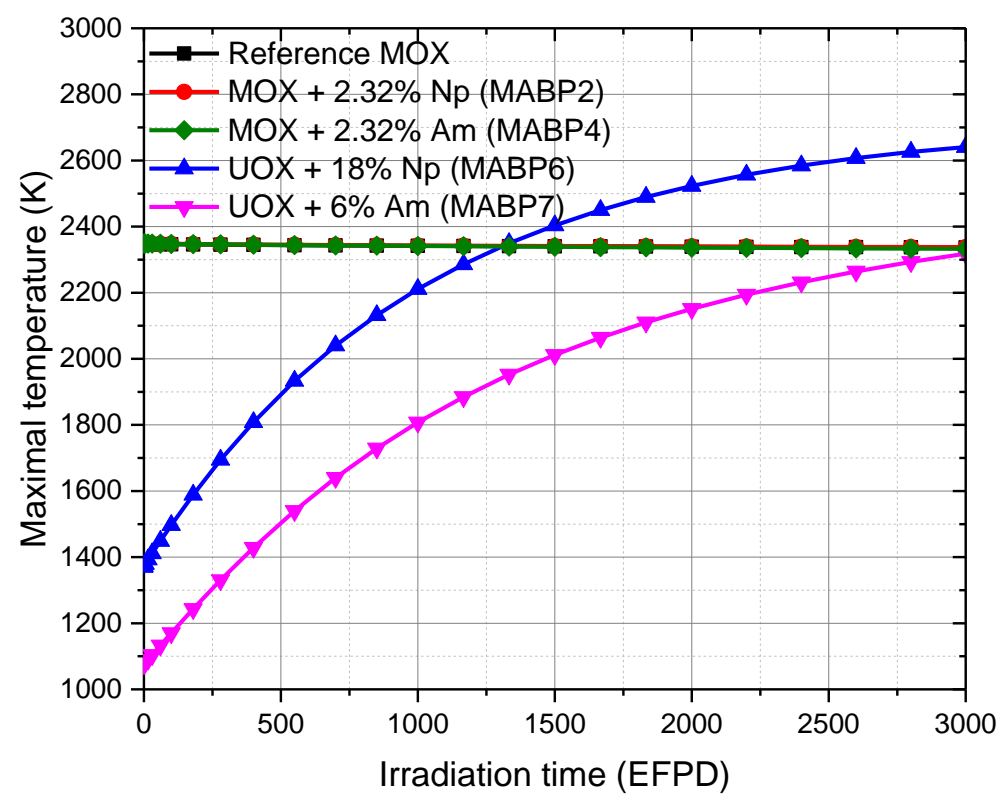

Fig. 8. Evolution of centerline temperature under irradiation 
The gas pressure in these pins is presented in Fig. 9. The pressure for the cases with addition of americium is $20 \%$ higher than the one that of reference pin, but still close to maximal allowance, because of helium released from ${ }^{242} \mathrm{Cm}$ decay.

Consequently, for the criterions of burn-up, margin to temperature and gas release, these designs satisfy current technological requirements under irradiation of neutrons until a 150 $\mathrm{GWd} / \mathrm{t}$ maximal burnup.

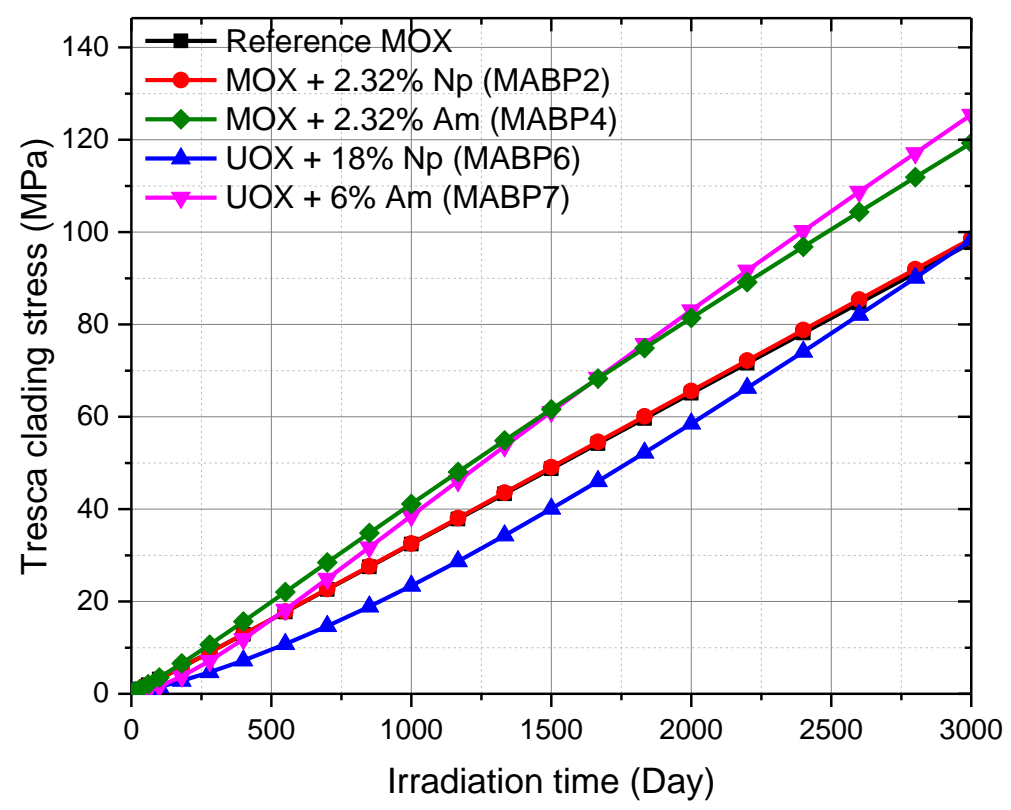

Fig. 9. Evolution of gas pressure in fuel pin under irradiation

\subsubsection{Characteristics during cooling}

After irradiation in the core, the depleted fuel cools down during the recycling processes in which several requirements must be followed to ensure that the designs discussed here are compatible with the current industrial background. The key characteristics during cooling, i.e. decay heat, activity and neutron source are obtained using the DARWIN2.3 code with a fuel composition corresponding to the discharged fuel with a $100 \mathrm{GWd} / \mathrm{t}$ burnup.

The decay heat from irradiated americium is higher but decreases quickly with time because the main contribution is from ${ }^{242} \mathrm{Cm}$ which has a half-life of 142 days. As shown in Fig. 10, except for the two hybrid designs with americium, all design satisfies current technological requirements on the decay heat removal i.e. $0.25 \mathrm{~W} / \mathrm{g}$ after 15 days cooling and $0.047 \mathrm{~W} / \mathrm{g}$ after 450 days cooling (See Section 3.2). The decay heat for these two hybrid designs is very close to the limit threshold. The cooling time can be adjusted to satisfy current requirements. For instance, MABP7 with $6 \%$ wt Am in UOX matrix needs additional 15 days before in-vessel fuel handing and 50 days before removal to water storage. MABP6, with18\%wt Np in UOX matrix, requires additional 150 days before it can be moved to water storage, which can be achieved within 2 cycles of in-vessel storage. 


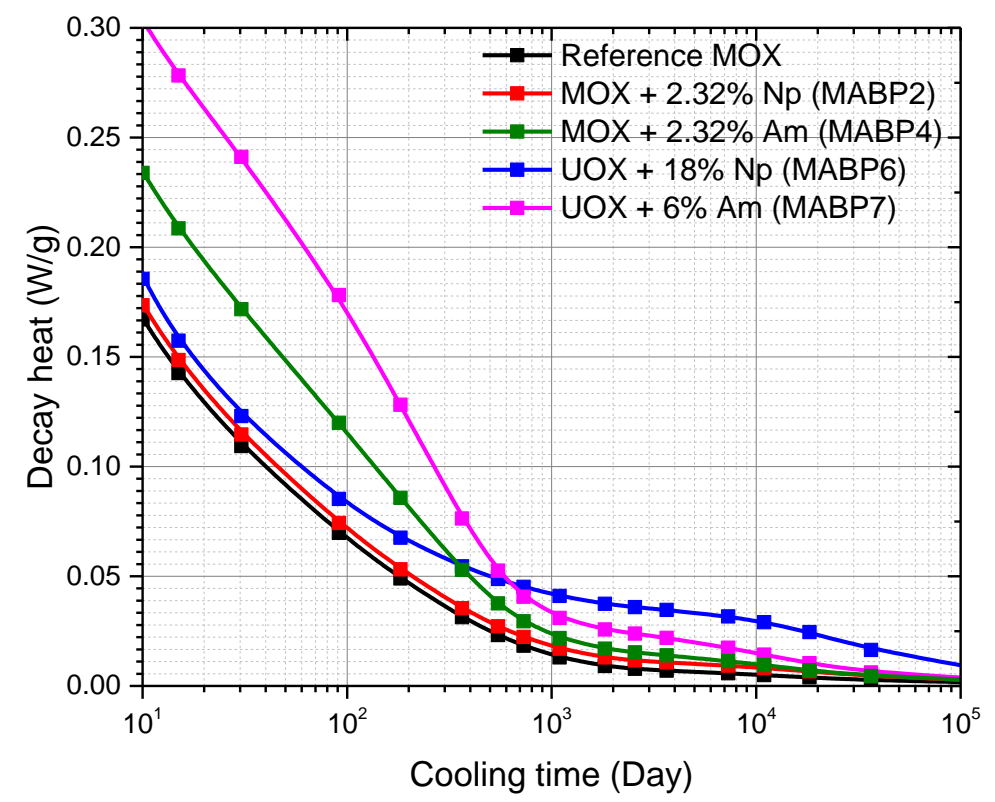

Fig. 10. Evolution of decay heat in fuel pin during cooling

The activity and neutrons source of these fuel pins are presented prospectively in Fig. 11 and Fig. 12. Regarding activity, these designs have no significant impact on the fuel recycling processes because their levels are very close to the reference MOX fuel. Neutrons source for the hybrid approach with americium is about 6 times as the reference MOX, but this would not be an issue because there are only 6 pins with addition of americium among 271 fuel pins in each fuel assembly. The neutron source for the homogeneous loading of americium is about 3 times as the reference MOX. Neutron sources hazard source is related to dose rates at transportation, storage and reprocessing stages. These potential issues should be investigated in the future.

The neptunium addition increases decay heat in long term while the americium addition increases both decay heat and neutron source. It appears that all these designs either satisfy current technological requirements or could be handled in foreseen fuel cycles facilities if a slightly extended cooling time is considered.

The spatial flux and power distribution for the hybrid design investigated in this section, shows no significant impact regarding the main technological criteria. The evolution of the main characteristics under irradiation (burn-up, fuel temperature and gas release) and during the cooling (decay heat, activity and neutron source) proves that these burnable poison designs satisfy current fuel technologies. 


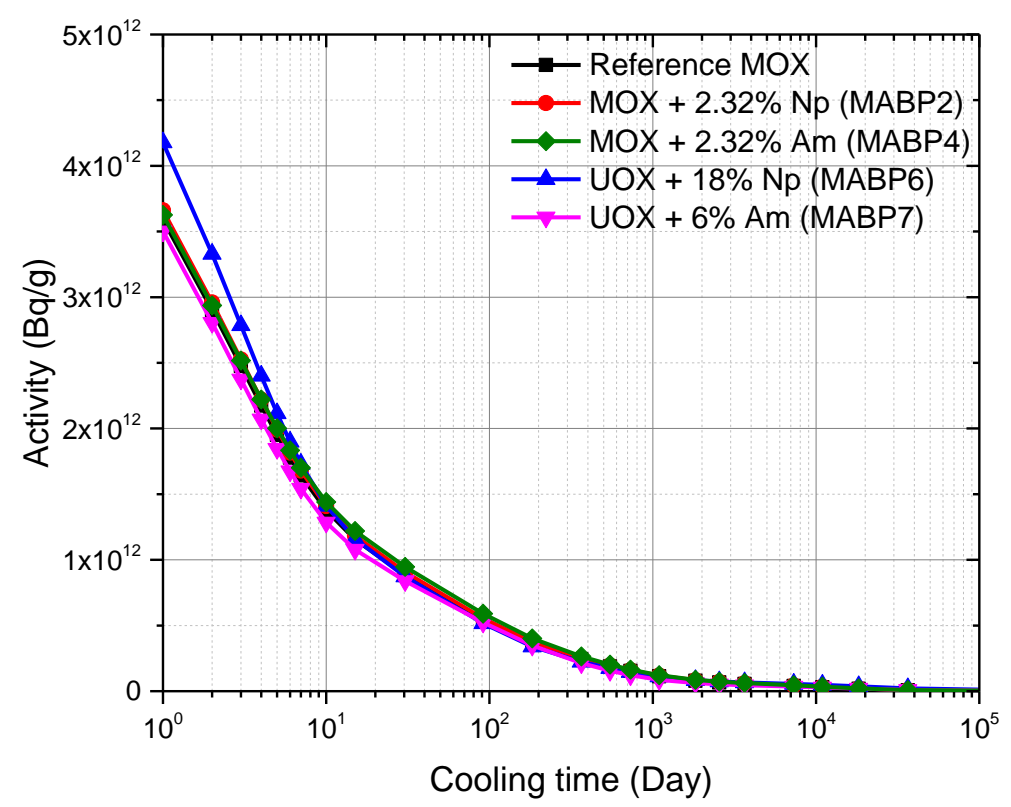

Fig. 11. Evolution of activity in fuel pin during cooling

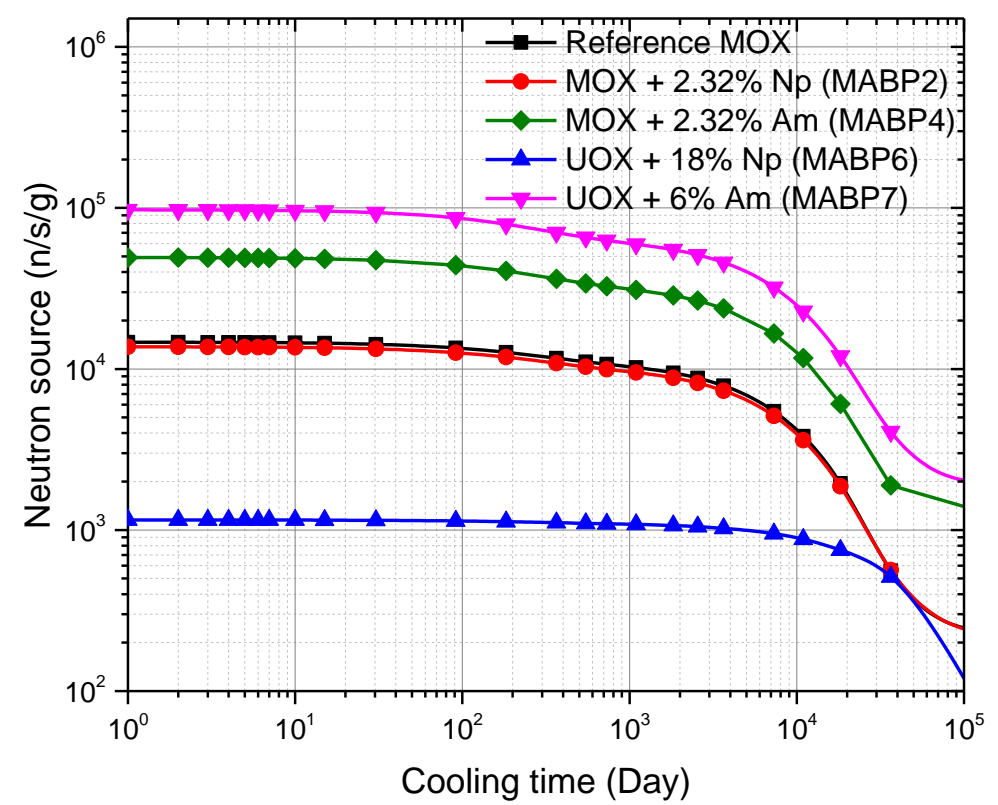

Fig. 12. Evolution of neutron source in fuel pin during cooling

\subsection{Influence on the core}

This section will study the impact of burnable poisons with minor actinides on the core performance including the materials balance, power distribution and feedback coefficients.

\subsubsection{Core material balance}

The objective of these burnable poison designs is to compensate for the reactivity, but it is also interesting to evaluate the core mass balance. The mass difference (of uranium, plutonium, 
americium and neptunium) between EOEC and BOEC for each design is shown in Table 5.

The reference core is in the self-breeding option in which a large quantity of uranium is consumed but without significant plutonium production. Nevertheless, the reference core design produces $53 \mathrm{~kg}$ americium and $8 \mathrm{~kg}$ neptunium at each equilibrium cycle.

With addition of minor actinides, an increase on the plutonium production is observed thereby less plutonium inventory in the new fuel is required. Furthermore, all the homogeneous loading cases and the neptunium hybrid loading case are net consumer of minor actinides.

The MABP7 corresponding to 6 UOX pins with $6 \% \mathrm{wt}$ americium, does reduce by $14 \mathrm{~kg}$ the core americium production but cannot achieve a net consumption of americium, therefor the hybrid mode requires $20 \sim 30$ such pins to realize zero production of americium in SFR-V2B core. However, the addition of americium would increase the product of curium. In summary, these designs show an interesting capability to reduce production even consume minor actinides, which should be investigated in the future.

Table 5. Mass balance at the equilibrium cycle (Unit: kg)

\begin{tabular}{cccccc}
\hline Design & $\mathrm{Np}$ & $\mathrm{U}$ & $\mathrm{Pu}$ & $\mathrm{Am}$ & $\mathrm{Cm}$ \\
\hline Reference & +8 & -1716 & +59 & +53 & +13 \\
MABP1 & -59 & -1691 & +102 & +52 & +15 \\
MABP2 & -188 & -1619 & +161 & +51 & +14 \\
MABP3 & +9 & -1710 & +106 & -16 & +30 \\
MABP4 & +9 & -1671 & +168 & -148 & +58 \\
MABP5 & +8 & -1731 & +74 & +52 & +15 \\
MABP6 & -28 & -1710 & +90 & +52 & +15 \\
MABP7 & +8 & -1733 & +86 & +39 & +18 \\
\hline
\end{tabular}

\subsubsection{Core power distribution}

For the reference SFR-V2B, the control rods CSD2 is inserted about $25 \mathrm{~cm}$ into fissile zone at $\mathrm{BOEC}$ which is reserved for the reactivity compensation function. However, the MABP1 core does not need this insertion of control rods to compensate for the reactivity loss. Consequently, the comparisons is drawn here between the BOEC of the reference core with rods $25 \mathrm{~cm}$ inserted, while the burnable poisons cases are considered without rod insertion.

The discrepancy in power distribution between the MABP1 core and the reference core varies between $-8.0 \%$ wt and $+6.6 \%$ wt at BOEC (See Fig. 13). As shown in Table 6, the maximal linear heat rating of reference design and MABP1 are respectively 445 and $449 \mathrm{~W} / \mathrm{cm}$ at BOEC. The main impact is located close to the position of control rods because of the change in control rods insertion.

The power density decrease forms the core center to the core periphery. After one cycle irradiation, CSD2 in the reference core is withdrawn to the top of fuel, which helps to increase the linear heating in the core periphery. However, MABP1 compensate for reactivity loss by 
using minor actinide and thus lacks of such power tuning from the control rods. Consequently, the linear heating in the periphery of MABP1 is lower than the reference core. The maximal linear heat rating of reference design and MABP1 are respectively 419 and $430 \mathrm{~W} / \mathrm{cm}$ at EOEC.

The MABP5, MABP6 and MABP7 have similar influence on the core power distribution by comparison with MABP1. The influence of MABP2, MABP3 and MABP4 on the power distributions are not considered because they are overqualified to compensate for the reactivity loss in SFR-V2B. The influence on the power distribution is origin from the position of control rods and is limited.
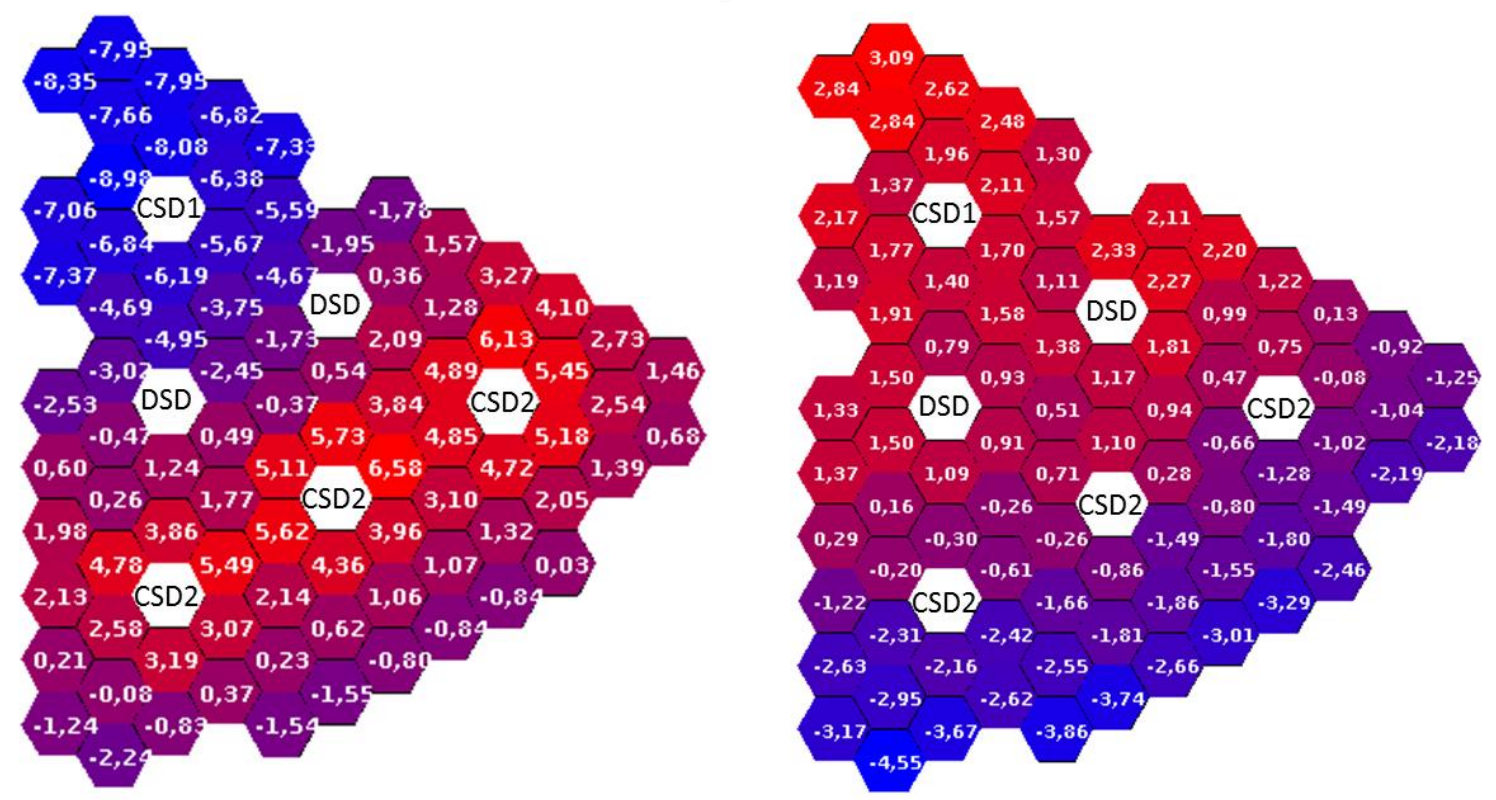

Fig. 13. The discrepancy in power distribution between MABP1 core and reference core (Units: \%)

Table 6. Maximal linear heat rating different cores $(\mathrm{W} / \mathrm{cm})$

\begin{tabular}{ccc}
\hline & BOEC & EOEC \\
\hline Ref & 445 & 419 \\
MABP1 & 449 & 430 \\
\hline
\end{tabular}

\subsubsection{Feedback coefficient}

The feedback coefficients, i.e. sodium void worth and Doppler constant, are compared for different cores (See Table 7). The loading of americium or neptunium to achieve burnable poison objective has only slight influence on the sodium void worth. On the other hand, both americium and neptunium weaken the Doppler Effect.

The core transient behavior can be analyzed based on these parameters. However, it appears that the impact of these burnable poison designs on the core safety performance is limited. 
Table 7. Core feedback coefficient at the end of equilibrium cycle (Unit: pcm)

\begin{tabular}{ccc}
\hline Design & Sodium void worth & Doppler constant \\
\hline Reference & 2123 & -916 \\
MABP1 & 2141 & -887 \\
MABP2 & 2253 & -783 \\
MABP3 & 2083 & -895 \\
MABP4 & 2080 & -800 \\
MABP5 & 2092 & -912 \\
MABP6 & 2121 & -883 \\
MABP7 & 2106 & -896 \\
\hline
\end{tabular}

These designs are applied for the burnable poison objective in this paper, but they do help transmutation of minor actinides. The impact on the core power distribution is limited and is origin from the position of control rods to compensate for the reactivity loss. These designs have little influence on the sodium void effect, but they weaken the Doppler Effect.

\section{Conclusions}

This paper studies the application of minor actinides as burnable poisons in the sodium fast reactors. Two loading modes of minor actinides is considered: the homogeneous one mixes minor actinides in all fuel and the hybrid one packages minor actinides in UOX matrix as independent and limited pins in fuel assembly. The maximum minor actinides content in these two loading modes are discussed by considering current technological limitations. Finally, the results of seven designs with minor actinides are presented.

Both homogeneous and hybrid loading modes show a satisfactory capability to compensate for the reactivity loss. For SFR-V2B core design considered in this study, the reactivity compensation ability of homogeneous modes studied in this paper vary from 415 pcm to 1525 pcm. If the reactivity compensation ability of hybrid modes is lower, it could show a good potential if more pins with minor actinides have to be used and/or if alternative matrix to UOX, such as zirconium, can be used. Moreover, this hybrid mode facilitates the management of minor actinides. The independent pins reduce the impact on the manufacture and the recycling stage. The loading mass can also be adjusted by mean of content or the pin number tuning.

Americium has better compensation ability than neptunium if same quantity is loaded. However, neptunium has less issues on the gas release, decay heat and neutron source, which enable quantitatively more a high content than americium.

Finally, the feasibility of these designs has been investigated both at assembly and core level. These designs meet current technological requirement on fuel pin design (thermomechanical behavior, constraints on fuel back end, etc.) and show only limited influence on the core performances. However, future studies, such as behavior under accidental transients and the fuel reprocessing scenario are required to assess the industrial viability of theses designs. 


\section{References}

Guo, H., Sciora, P., Kooyman, T., Buiron, L., Application of boron carbide as burnable poison in sodium fast reactors, one manuscript submitted to Nuclear Technology.

Archier, P., Palau, J.-M., Vidal, J.-F., 2016. Validation of the Newly Implemented 3D TDTMOC Solver of APOLLO3 Code on a Whole 3D SFR Heterogeneous Assembly. Presented at the PHYSOR 2016, Idaho USA.

Bussac, J., Reuss, P., 1978. Traité de neutronique: physique et calcul des réacteurs nucléaires avec application aux réacteurs à eau pressurisée et aux réacteurs à neutrons rapides. Hermann.

Chabert, C., Warin, D., Leudet, A., Milot, J.F., Saturnin, A., Lagrange, M.H., Hoorelbeke, J.M., 2012. Impact of minor actinide transmutation options on interim storage and geological disposal: The French Case, in: TWELFTH INFORMATION EXCHANGE MEETING ON PARTITIONING AND TRANSMUTATION. Prague, Czech Republic.

Chenaud, M., Devictor, N., Mignot, G., Varaine, F., VéNard, C., Martin, L., Phelip, M., Lorenzo, D., Serre, F., Bertrand, F., Alpy, N., Le Flem, M., Gavoille, P., Lavastre, R., Richard, P., Verrier, D., Schmitt, D., 2013. Status of the ASTRID core at the end of the pre-conceptual design phase 1. Nucl. Eng. Technol. 45, 721-730.

Coquelet-Pascal, C., Meyer, M., Girieud, R., Tiphine, M., Eschbach, R., Chabert, C., Garzenne, C., Barbrault, P., Gannaz, B., Durpel, L.V.D., Favet, D., Caron-Charles, M., Carlier, B., Lefèvre, J.-C., 2015. Scenarios for Fast Reactors Deployment with Plutonium Recycling.

Golfier, H., Lenain, R., Calvin, C., Lautard, J.J., Baudron, A.M., Fougeras, P., Magat, P., Martinolli, E., Dutheillet, Y., 2009. APOLLO3®: A common project of CEA, AREVA and EDF for the development of a new deterministic multi-purpose code for core physics analysis. Presented at the International Conference on Mathematics, Computational Methods and Reactor Physics (M\&C 2009), Saratoga Springs, New York, USA.

Grouiller, J.-P., Pillon, S., de Saint Jean, C., Varaine, F., Leyval, L., Vambenepe, G., Carlier, B., 2003. Minor actinides transmutation scenario studies with PWRs, FRs and moderated targets. J. Nucl. Mater., Proceedings of the 2nd Seminar on European Research on Materials for Transmutation 320, 163-169. https://doi.org/10.1016/S0022-3115(03)00184-3

Guo, H., Martin, G., Buiron, L., 2018. Improvement of sodium fast reactor control rods calculations with APOLLO3. Presented at the ICAPP 2018, Charlotte, North Carolina, USA.

Kooyman, T., Buiron, L., Rimpault, G., 2018. A comparison of curium, neptunium and americium transmutation feasibility. Ann. Nucl. Energy 112, 748-758.

https://doi.org/10.1016/j.anucene.2017.09.041

Mignot, G., Klein, J.C., Chenaud, M.S., Thevenot, C., Ravenet, A., Valentin, M.P.B., Masoni, P., Dubuisson, P., Delafontaine, S., Nicolas, L., Verrier, D., Scholer, A.C., Ruah, D., Garat, V., Lecarpentier, D., Tetart, P., Maliverney, B., Massara, S., 2008. Studies on french SFR advanced core designs. Presented at the ICAPP, Anaheim, CA, USA.

Moller, J.Y., Lautard, J.J., Schneider, D., 2011. Minaret, a deterministic neutron transport 
solver for nuclear core calculations. Presented at the M\&C 2011, Rio de Janeiro, RJ, Brazil.

OECD, 2012. Homogeneous versus Heterogeneous Recycling of Transuranics in Fast Nuclear Reactors, Nuclear Science. OECD Publishing. https://doi.org/10.1787/9789264991774-en

PALMIOTTI, G., SALVATORES, M., ASSAWAROONGRUENGCHOT, M., 2011. Impact of the Core Minor Actinide Content on Fast Reactor Reactivity Coefficients. J. Nucl. Sci. Technol. 48, 628-634. https://doi.org/10.1080/18811248.2011.9711743

Ronchi, C., Ottaviani, J.., Degueldre, C., Calabrese, R., 2003. Thermophysical properties of inert matrix fuels for actinide transmutation. J. Nucl. Mater. 320, 54-65.

https://doi.org/10.1016/S0022-3115(03)00171-5

Schneider, D., Dolci, F., Gabriel, F., Palau, J.M., Guillo, M., Pothet, B., Archier, P., Ammar, K., Auffret, F., Baron, R., 2016. APOLLO3: CEA/DEN deterministic multi-purpose code for reactor physics analysis. Unifying Theory Exp. 21st Century PHYSOR 2016 Sun Val. Ida. U. S.

Sciora, P., Buiron, L., Rimpault, G., Varaine, F., 2009. A break even oxide fuel core for an innovative SFR: CEA neutronic studies.

Tsilanizara, A., Diop, C.M., Nimal, B., Detoc, M., Lunéville, L., Chiron, M., Huynh, T.D., Brésard, I., Eid, M., Klein, J.C., Roque, B., Marimbeau, P., Garzenne, C., Parize, J.M., Vergne, C., 2000. DARWIN: An Evolution Code System for a Large Range of Applications. J. Nucl. Sci. Technol. 37, 845-849. https://doi.org/10.1080/00223131.2000.10875009 